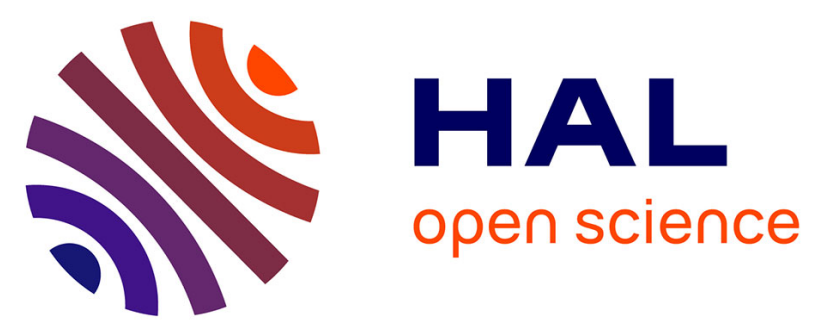

\title{
Identification of ductile to brittle transition temperature by using plane strain specimen in tensile test and correlation with instrumented Charpy impact test: experimental and numerical study
}

Frank Tioguem, Matthieu Mazière, Franck Tankoua, André Galtier, Anne-Françoise Gourgues-Lorenzon

\section{To cite this version:}

Frank Tioguem, Matthieu Mazière, Franck Tankoua, André Galtier, Anne-Françoise GourguesLorenzon. Identification of ductile to brittle transition temperature by using plane strain specimen in tensile test and correlation with instrumented Charpy impact test: experimental and numerical study. Mechanics \& Industry, 2018, 19 (1), 107, 11 p. 10.1051/meca/2017034 . hal-01869103

\section{HAL Id: hal-01869103}

https: / hal-mines-paristech.archives-ouvertes.fr/hal-01869103

Submitted on 6 Sep 2018

HAL is a multi-disciplinary open access archive for the deposit and dissemination of scientific research documents, whether they are published or not. The documents may come from teaching and research institutions in France or abroad, or from public or private research centers.
L'archive ouverte pluridisciplinaire HAL, est destinée au dépôt et à la diffusion de documents scientifiques de niveau recherche, publiés ou non, émanant des établissements d'enseignement et de recherche français ou étrangers, des laboratoires publics ou privés. 


\title{
Identification of Ductile to Brittle Transition Temperature by using Plane Strain specimen in Tensile Test and Correlation with Instrumented Charpy Impact Test: Experimental and Numerical study
}

\author{
Frank TIOGUEM ${ }^{\mathrm{a}}{ }^{1,2}$, Matthieu MAZIERE ${ }^{1}$, Franck TANKOUA ${ }^{2}$, André GALTIER ${ }^{2}$ \\ and Anne-Françoise GOURGUES-LORENZON ${ }^{1}$ \\ ${ }^{1}$ MINES ParisTech, PSL Research University, MAT - Centre des matériaux, CNRS UMR 7633, BP87 91003 Evry cedex, \\ France \\ ${ }^{2}$ ASCO Industries - Centre de Recherche CREAS, BP 70045, Avenue de France, 57301 Hagondange cedex, France
}

\begin{abstract}
This study addresses the correlation between the ductile-to-brittle transition (DBT) temperature ranges of high strength 4140 steel obtained respectively from tensile tests under plane strain (PS) conditions and from conventional Charpy Impact tests. Specimens were taken respectively at $25 \mathrm{~mm}(\mathrm{P})$ and at 55 $\mathrm{mm}(\mathrm{M})$ from skin of a cylindrical $90-\mathrm{mm}$-radius hot rolled bar water quenched from $875^{\circ} \mathrm{C}$, tempered at $600^{\circ} \mathrm{C}$ and air cooled. $\mathrm{P}$ and $\mathrm{M}$ samples respectively showed a fully martensitic and a martensitebainite microstructure. Fracture surface observations showed good agreement for physical fracture mechanisms (cleavage facet size, mixed ductile + brittle fracture in the transition region, ductile fracture at higher temperatures) between PS and Charpy, in particular sensitivity of upper bainite to cleavage fracture that reduces fracture energy in the lower shelf-energy on Charpy tests.
\end{abstract}

Key words: Martensite-bainite / Carbides / Charpy test / Notched plane-strain specimen / Experimental and numerical study

\section{Introduction}

High strength, quenched and tempered steels have been largely used since decades for manufacturing of off-shore drilling parts and many components of automotive gearboxes. High yield strength and good impact toughness are required as design criteria for such applications. Yet, as reviewed by e.g. Beranger et al. [1], improving strength of these steels generally implies decreasing their impact toughness. The mechanical properties of this steel can be tuned by improving their final heat treatment [2]. In certain cases, an increase in tempering temperature is shown to increase impact toughness in the upper self-energy (USE) range, yet at the expense of yield strength. Improving the trade-off between these two mechanical properties is therefore required to optimize in-service properties of components. The two microstructural components that have to be optimized in this way are (i) the martensitic matrix and (ii) the population of carbides that are formed during tempering.

The present study focuses on a 1\%Cr-Mo AISI 4140 steel. After final normalizing, quenching and tempering, it is known to present a mixed structure of tempered martensite and lower bainite that is also known to improve yield stress and tensile strength up to about $30 \%$ in spite of only martensite matrix.

\footnotetext{
${ }^{\text {a }}$ Corresponding author : frank.tioguem-teagho@mines-paristech.fr
} 
Tomita [3] shows that a previous high temperature thermomechanical treatment (HTMT) improves USE with respect to deformation-free heat treatment on 4340 steel. The improved mechanical properties are attributed to the sub-cell structure introduced in austenite by processing HTMT and inherited martensite. In a tempered martensitic steel $(0.3 \mathrm{C}-0.5 \mathrm{Si}-2 \mathrm{Mn}-0.001 \mathrm{P}-0.001 \mathrm{~S})$, Takebayashi et al. [4] showed that refining microstructural parameters such as the prior austenite grain size improved the USE going up to $30 \mathrm{~J}$, but no significant effect of carbide size distribution was mentioned in this study. Im et al. [5] showed that increasing molybdenum and reducing the carbon content can improve the USE, by enhancing precipitation of $\mathrm{M}_{2} \mathrm{C}$-type alloy carbides instead of cementite, whose size is much lower than the critical carbide size to initiate fracture. In the Im's study, observations of polished fracture surface from tensile tests at ductile fracture region using roundnotched cylindrical specimens revealed that the vicinity of $\mathrm{M}_{3} \mathrm{C}$ are major initiated site of cracks.

Charpy impact testing is a powerful tool to study the ductile-to-brittle transition (DBT) of bodycentered cubic (bcc) materials as a function of temperature but mechanical analysis of the test is difficult due to self-heating, strain rate sensitivity and contact issues. Moreover, the link between impact toughness and fracture toughness is not obvious in many cases, in particular, for bainitic and martensitic steel microstructures. The local approach to fracture has been introduced to solve this issue as reviewed by Pineau et al. [6]. In this approach, identification of the resistance of the material to fracture requires taking the heterogeneity of the microstructure into account. The local approach to fracture is classically based on tensile tests on notched cylindrical specimens. However, in high strength alloys reinforced by precipitation ductile fracture might be sensitive not only to the stress triaxiality ratio, $\eta$ (ratio of the hydrostatic stress to the von Mises equivalent stress) but also to the third invariant of the stress tensor, as commonly represented by the Lode angle, $\theta$ [7]. In fact, changing the geometry of specimens from round notched bars $(\cos (3 \theta)=1)$ to plane strain specimens $(\cos (3 \theta)=0)$ [8] can lead to applying a stress state closer to that experienced in Charpy three-point-bending specimens, both in terms of triaxiality and Lode parameter. To this aim, a new experimental approach making use of double side notched plane strain specimens is proposed in this study. The numerical analysis of tests on these specimens is expected to be much easier than that of Charpy tests.

The purpose of the present study is to investigate correlations between the DBT behavior of a high strength 4140 steel obtained respectively from tensile tests under plane strain conditions and from conventional Charpy impact tests. The effect of microstructure (both of matrix and carbides) on the ductile fracture behavior in the USE domain, the fracture mechanisms and the state stress are also addressed.

\section{Experimental procedures}

\subsection{Material and metallographic procedures}

The chemical composition of the steel is given in Table 1. Two samples of the same cylindrical bar were taken respectively at $25 \mathrm{~mm}(\mathrm{P})$ and at $55 \mathrm{~mm}(\mathrm{M})$ from the skin of a cylindrical $90 \mathrm{~mm}$ radius hot rolled bar water quenched from $875^{\circ} \mathrm{C}$, tempered at $600^{\circ} \mathrm{C}$ and air cooled. $\mathrm{P}$ and $\mathrm{M}$ microstructures respectively showed fully martensitic and a martensite-bainite matrix, with carbides particles. The average Vickers micro-hardness (weight $300 \mathrm{~g}$, dwell time 10s) of the two microstructures was $\mathrm{HV}_{0.3}=$ $344 \pm 15$ for microstructure $\mathrm{P}$ and $\mathrm{HV}_{0.3}=316 \pm 30$ for microstructure $\mathrm{M}$. 
Table 1: Chemical composition of AISI 4140 steel (wt. \%)

\begin{tabular}{ccccccccc}
\hline $\mathrm{C}$ & $\mathrm{Mn}$ & $\mathrm{Si}$ & $\mathrm{Ni}$ & $\mathrm{Mo}$ & $\mathrm{Cu}$ & $\mathrm{P}$ & $\mathrm{S}$ & $\mathrm{Al}$ \\
\hline 0.401 & 1.143 & 0.274 & 0.20 & 0.32 & 0.11 & 0.011 & 0.005 & 0.018 \\
\hline
\end{tabular}

For metallographic analysis, samples were polished to final $1 \mu \mathrm{m}$ diamond paste then etched in a $4 \%$ nital solution. In order to investigate the size distribution of carbides in detail, the plane perpendicular to the bar axis was chosen. Carbon extractive replicas was prepared by the same polishing and etching procedure, then coating the sample surface with a 50-nm-thick carbon film by using a QUORUM Q150T evaporator. The film was released from the sample by immersion in a $10 \%$ nital solution. The expected nature of carbides in such Cr-Mo quenched + tempered steels is composed of larger, rod-like or spherical $\mathrm{M}_{3} \mathrm{C}$ [5] together with smaller, needle-like $\mathrm{M}_{2} \mathrm{C}$ if the tempering temperature and time are respectively larger than $600^{\circ} \mathrm{C}$ and $100 \mathrm{~h}$.

Microstructural observations, including carbide distribution on extracted replicas and fracture surface observations were conducted using a Sigma300 and a FEI Nova NanoSEM 450 field-emission gun SEMs. From scanning electron microscope (SEM) images of the replicas, distributions of particle size and of the nearest-neighbor distance between carbides were estimated. Carbide size distributions were determined using common thresholding procedures of the Image ${ }^{\circledR}$ software. Two parameters were considered during particle analysis for discrimination, the size and the cylindricity. The nearestneighbor distance between carbides were calculated by the SKIZ geodesic method which is based on mathematical morphology considerations, with Matlab ${ }^{\circledR}$ software; this method takes the shape and the border of each particles in addition with the center of mass for estimation of the neighbor distance. Several thousands of particles were analyzed for each microstructure.

\subsection{Mechanical tests}

To characterize the DBT behavior of both microstructures, instrumented Charpy impact tests (ICITs) were performed first using 2 mm-deep V-notched specimens $\left(10 \times 10 \times 55 \mathrm{~mm}^{3}\right)$. Three specimens were broken at each test temperature ranging from $-60^{\circ} \mathrm{C}$ to $+60^{\circ} \mathrm{C}$. An instrumented impact pendulum device, with a nominal impact velocity of $5 \mathrm{~m} . \mathrm{s}^{-1}$ was used.

Two kinds of quasistatic tensile tests were performed along longitudinal direction of the bar by using a $250 \mathrm{kN}$ servohydraulic Instron 8500 machine. First, tests at room temperature were performed at prescribed elongation rate of $10^{-3} \mathrm{~s}^{-1}$ on smooth cylindrical (SC, Fig 1a) and smooth plane strain (SPS, Fig. 1b) specimens. To identify the DBT behavior in plain strain conditions by the local approach of fracture, tensile tests were performed on double-side notched plane-strain (NPS) specimens (Fig. 1c) in a climatic chamber at $-60^{\circ} \mathrm{C},-20^{\circ} \mathrm{C},+20,+60^{\circ} \mathrm{C}$. The specimen temperature was controlled to $\pm 1{ }^{\circ} \mathrm{C}$ by using a thermocouple spot welded on the specimen end. A MTS extensometer of $10 \mathrm{~mm}$ gauge length was attached to one side of NPS specimens in order to monitor notch opening. 


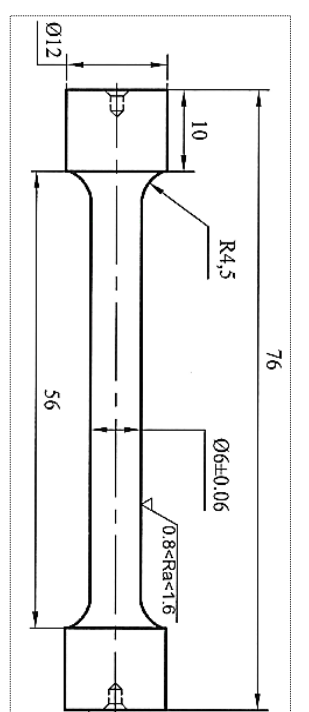

(a)

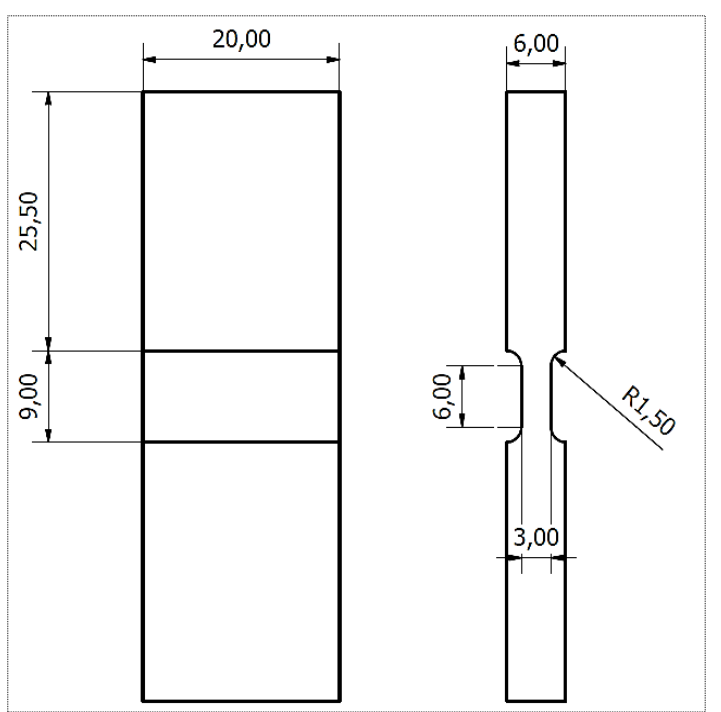

(b)

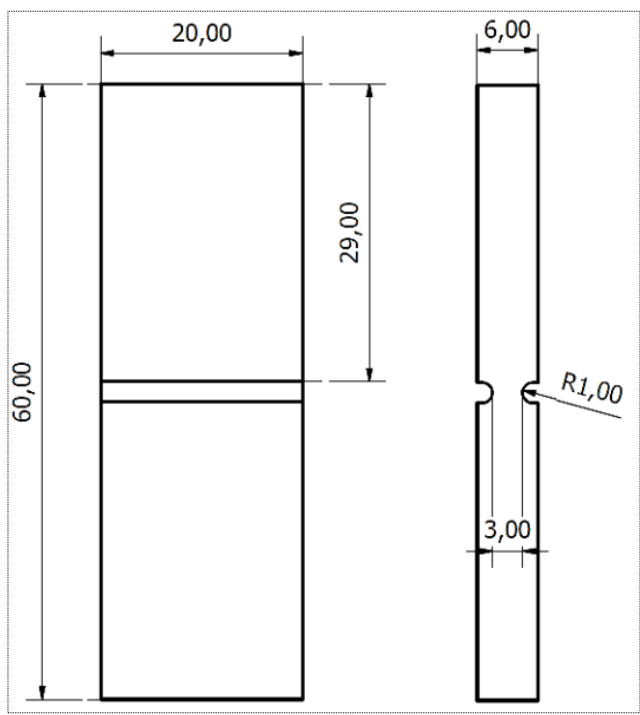

(c)

Fig. 1: Dimensions (in mm) of (a) SC. (b) SPS and (c) NPS specimens. All dimensions in mm.
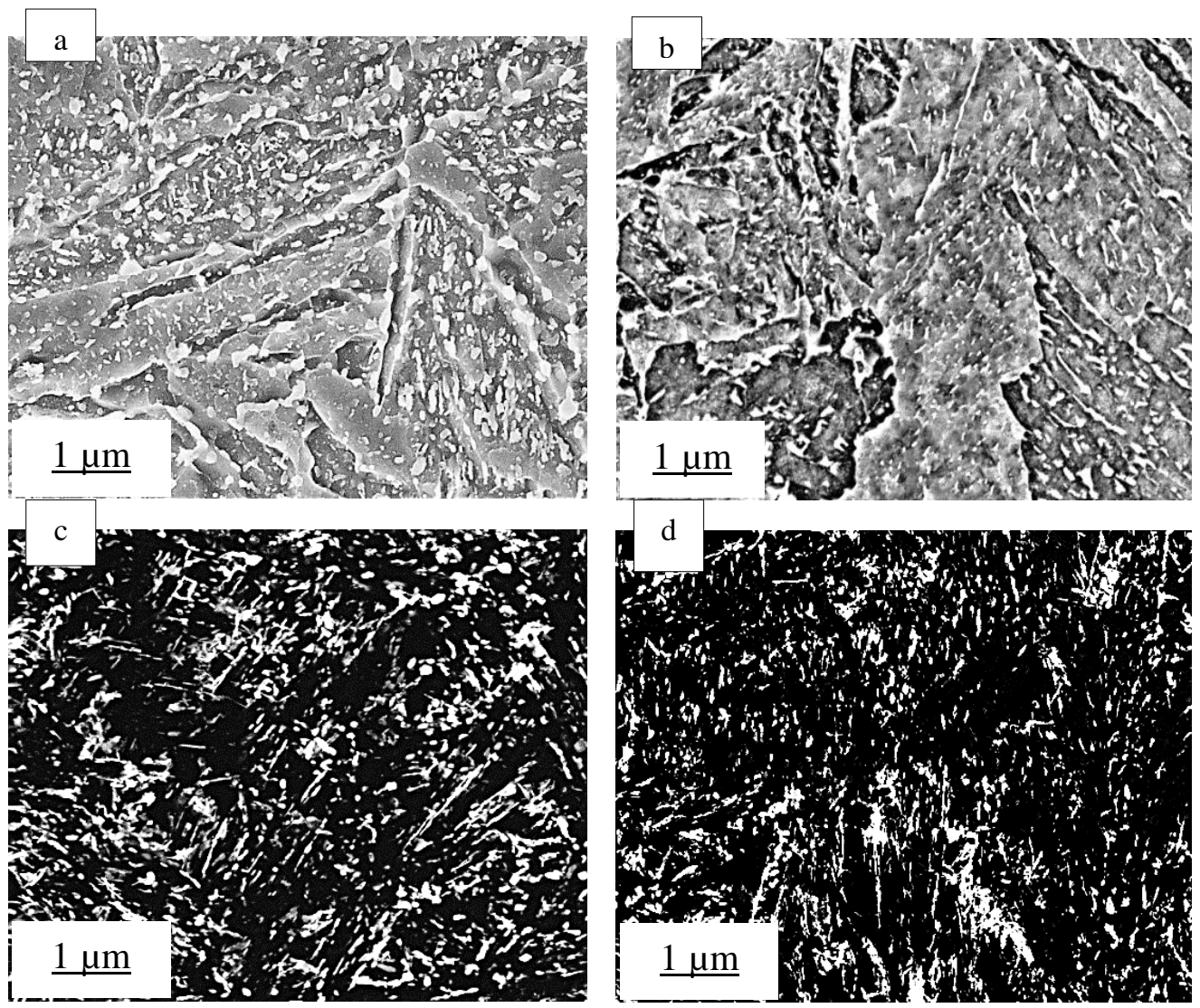

Fig. 2: Typical SEM images of etched samples of (a) P and (b) M microstructures. Typical SEM images of extractive replicas of (c) P and (d) M microstructures. 


\section{Results}

\subsection{Microstructure and carbide distributions}

As shown in Fig. 2, $\mathrm{P}$ and $\mathrm{M}$ microstructures show martensite laths and mixed martensite and bainite, respectively. Considering the tempering temperature $\left(600^{\circ} \mathrm{C}\right)$, it seems to be upper bainite. Several types of carbides were identified within the matrix. Detailed analysis of carbon replicas showed coarser, elongated rod-like particles that could be $\mathrm{M}_{3} \mathrm{C}$ carbides; there were also needle-like $\mathrm{M}_{3} \mathrm{C}$ type carbides.

The results of statistical analysis on images from extraction replicas are presented in Fig. 3. About 2,000 particles were analyzed for the size distribution of $\mathrm{M}_{3} \mathrm{C}, 15,000$ nearest-neighbor distances between $\mathrm{M}_{3} \mathrm{C}$ carbides for each of the $\mathrm{P}$ and $\mathrm{M}$ microstructures. SKIZ method allows the determination of nearest-neighbor distances between $\mathrm{M}_{3} \mathrm{C}$ carbides while taking the shape of the carbides into account. All the results are presented in table 2.

Except for some coarser $\mathrm{M}_{3} \mathrm{C}$ particles found in the $\mathrm{P}$ microstructure, the carbide size distribution was rather similar in the two microstructures. The distance between $\mathrm{M}_{3} \mathrm{C}$ carbides did not strongly depend on microstructure, even if there was a slight difference between P and M microstructures.

Table 2: Result of carbide size and nearest-neighbor distribution distance analysis.

\begin{tabular}{ccc}
\hline Microstructure & $\begin{array}{c}\mathrm{M}_{3} \mathrm{C}(\text { mean } \\
\text { diameter, } \mu \mathrm{m})\end{array}$ & $\begin{array}{c}\mathrm{M}_{3} \mathrm{C} \text { (mean nearest- } \\
\text { neighbor distance, } \mu \mathrm{m})\end{array}$ \\
\hline $\mathrm{P}$ & 0.20 & 0.15 \\
\hline $\mathrm{M}$ & 0.17 & 0.20 \\
\hline
\end{tabular}
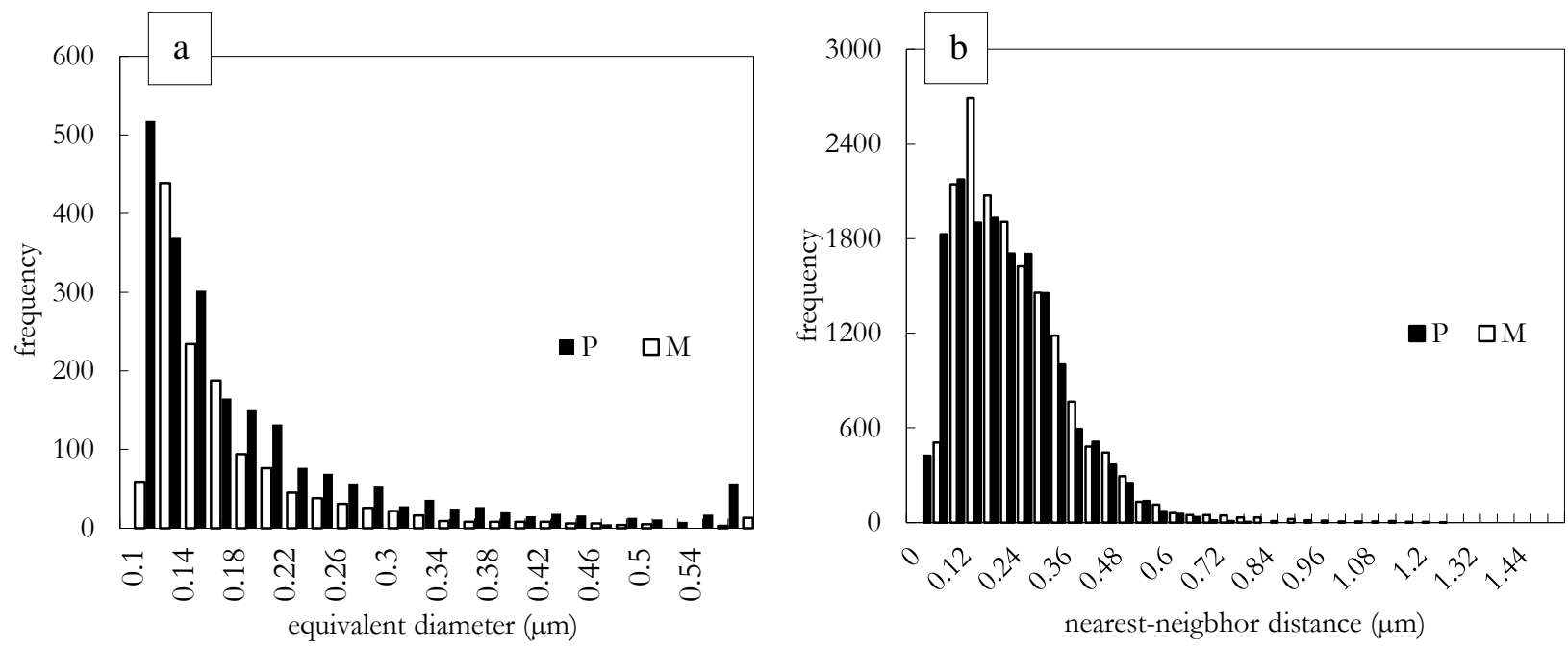

Fig. 3: Results of statistical analysis on $\mathrm{M}_{3} \mathrm{C}$ carbides, (a) carbide size distribution, (b) distribution of nearest-neighbor distances between carbides for $\mathrm{P}$ and $\mathrm{M}$ specimens, respectively. 


\subsection{Tensile properties of smooth specimens}

Fig. 4 shows the tensile curves of $\mathrm{P}$ and $\mathrm{M}$ microstructures at room temperature. Based on conventional tensile tests on SC specimens (Fig. 4a), the general tensile properties of materials are respectively for $\mathrm{P}$ and $\mathrm{M}$ microstructures: yield strength 900 and $720 \mathrm{MPa}$, tensile strength 1050 and $950 \mathrm{MPa}$, maximum uniform elongation 0.058 for both, fracture elongation close to 0.16 for both. Thus, microstructure $\mathrm{P}$ was stronger than microstructure $\mathrm{M}$, but they displayed similar ductility. Tensile tests on SPS specimens, Fig. 4b were performed to facilitate identification of constitutive parameters. Plane strain tensile results confirmed that microstructure $\mathrm{P}$ was stronger than microstructure $\mathrm{M}$. Anyway, there was a slight difference in maximum uniform axial elongation in SPS specimens between the two microstructures $(4.3 \%$ at $1130 \mathrm{MPa}$ for microstructure $\mathrm{P}$ and $4 \%$ at $1000 \mathrm{MPa}$ for microstructure M).
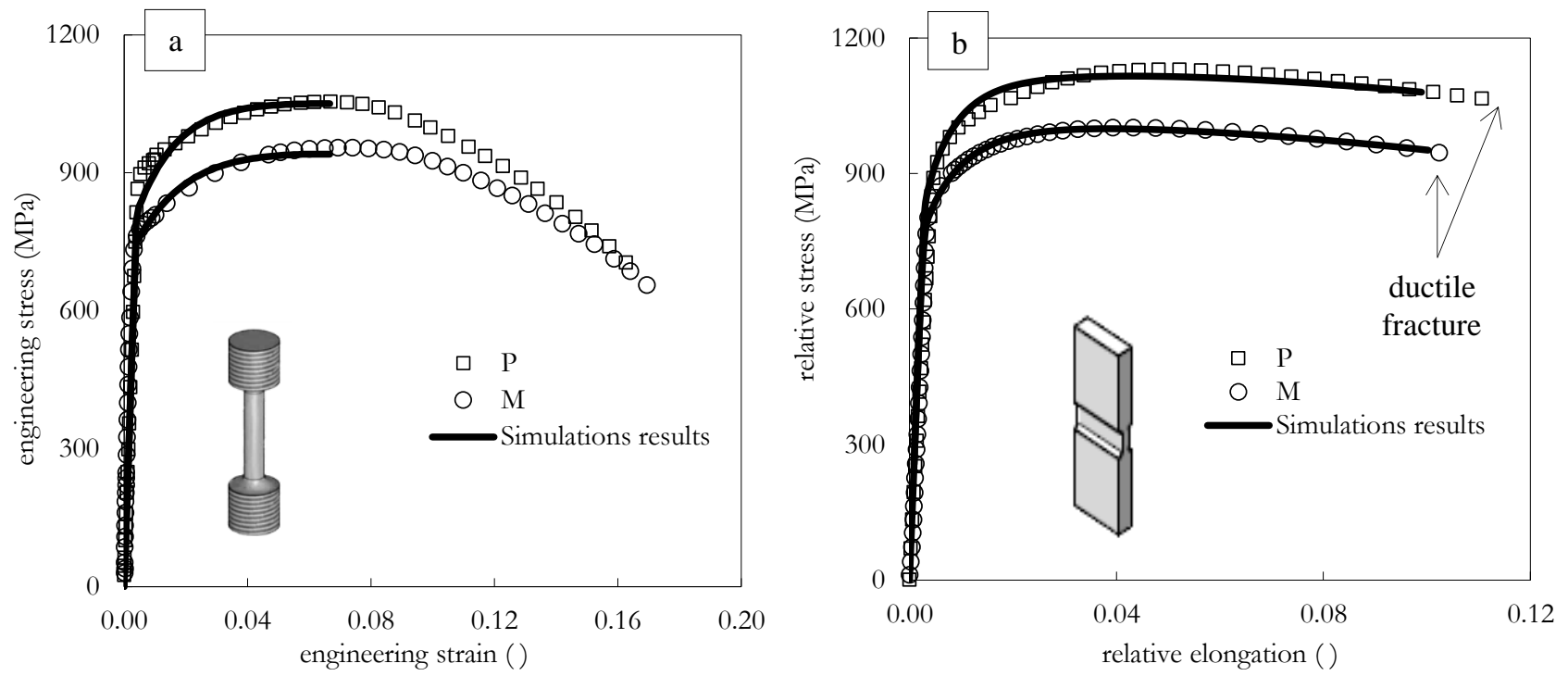

Fig. 4: Axial stress vs. axial elongation curves for tensile tests on: (a) SC and (b) SPS specimens. Symbols: experiments; lines: model predictions.

\subsection{Charpy impact properties}

\subsubsection{General behavior and associated fracture mechanisms}

Typical load vs. hammer displacement curves from ICI tests are reported in Fig. 5. These curves were divided into two parts [10]. In the first part, the load increase up to the maximum value, $F_{\max }$, this point being attributed to fracture initiation. In the second part of the curve, the load decreases steadily or abruptly up to the end of the test, due to crack propagation and final fracture. As reviewed in [4], the shape of this curve strongly depend on the test temperature. Abrupt load drops were attributed to brittle, unstable crack propagation, whereas ductile fracture generally induces a stable decrease in the load vs. displacement curve. This was actually the case for the considered steel; Charpy specimens associated to significant load drops in the curve exhibited a significant area fraction of flat brittle fracture (see 
general views of Fig. 5). Screenivasan et al [11] investigated martensitic stainless steel and categorized the ICIT waveform of a martensitic stainless steel into 3 types: type I, II and III, which correspond to brittle, mixed (brittle + ductile) and fully ductile fracture, respectively. The fracture surfaces, illustrated in Figs $5 \mathrm{a}$ and $5 \mathrm{~b}$ for specimens broken at $-60^{\circ} \mathrm{C},-20^{\circ} \mathrm{C}$ and $+20^{\circ} \mathrm{C}$, clearly agreed with this interpretation. The DBT curves of $\mathrm{P}$ and $\mathrm{M}$ microstructures, both in absorbed energy and area fraction of brittle fracture, are reported in Fig. 6.
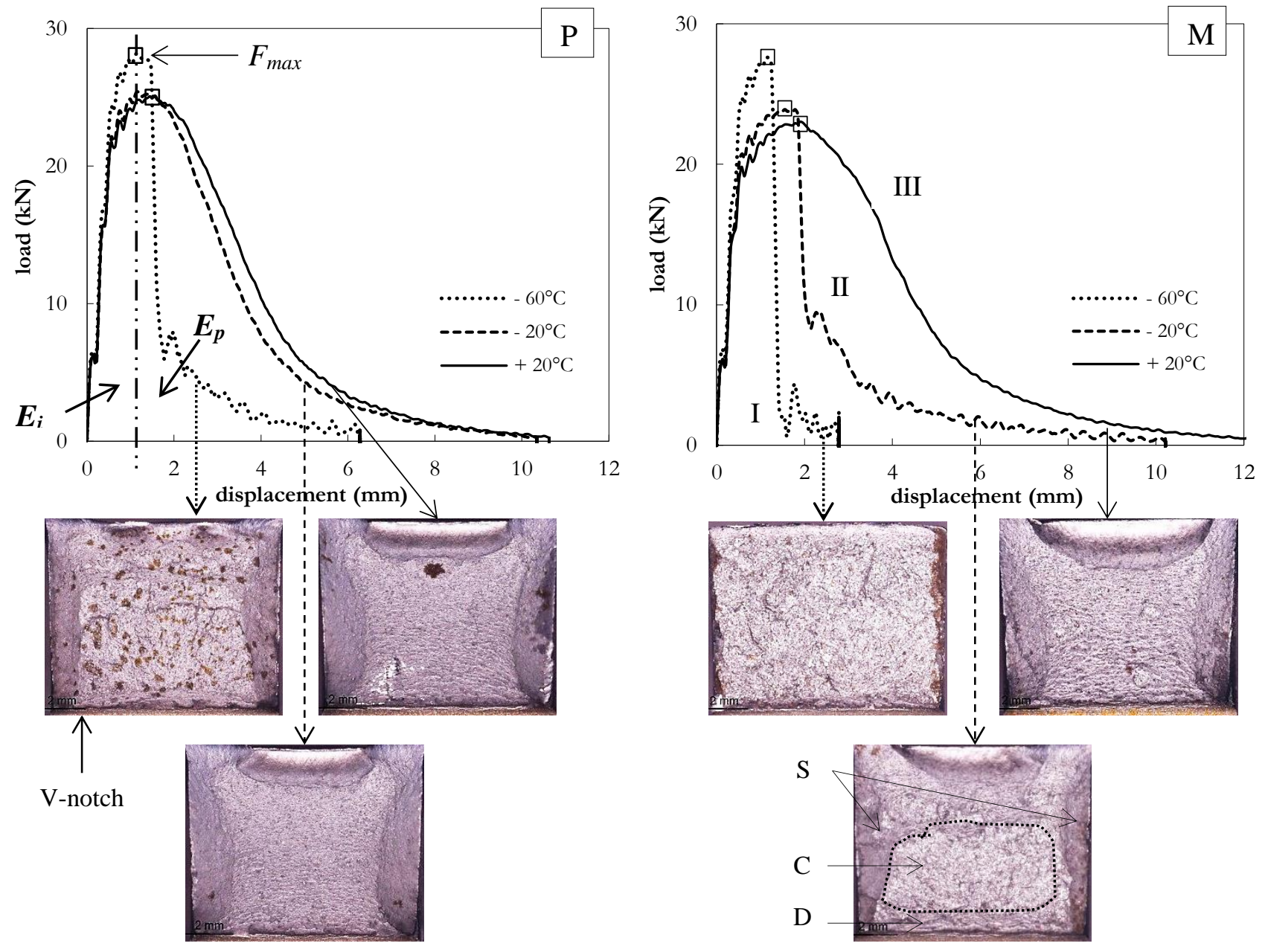

Fig. 5: Typical ICIT curves of (a) P and (b) M microstructures, together with global view of fractured specimens. The crack propagated from the bottom to the top of the images. D: flat ductile, C: cleavage, S: slant fracture.

For both $\mathrm{P}$ and $\mathrm{M}$ microstructures, the load vs. displacement curves obtained at $-60^{\circ} \mathrm{C}$ corresponded to type I. Fracture surface were globally brittle, although there were also many ductile regions close to the sides of the fractured specimens. Type II curves were obtained at $-20^{\circ} \mathrm{C}$; yet, the waveform of steel $\mathrm{M}$ at this test temperature presented a larger load drop than that of microstructure $\mathrm{P}$. On the corresponding fracture surface, the larger load drop was correlated to the presence of a wider brittle region than on the fracture surface of microstructure $\mathrm{P}$ at the same test temperature. Specimens corresponding to type III curves underwent fully ductile fracture, and were mainly obtained at room temperature. Moreover, for all these ductile specimens, a macroscopic wave-like shape of the fracture 
surface was noticed, from the notch tip up to the opposite side of the specimen. This could possibly be associated to strong strain localization in the plastic zones of the propagating crack but this point needs to be investigated in more detail before drawing any further conclusion.

The impact energy deduced from ICITs was obtained by calculation of the area under the load vs. displacement curves and corresponded to the total fracture energy. As shown in Fig. 6, both $\mathrm{P}$ and $\mathrm{M}$ microstructures tended to have the same transition temperature of about $-20^{\circ} \mathrm{C}$. As mentioned by e.g. Haušild et al [12], experimental data in the transition region generally show scatter. Microstructure M showed a higher upper shelf energy $(116 \mathrm{~J})$ than microstructure $\mathrm{P}(100 \mathrm{~J})$. On the contrary, the fracture energy in the lower temperature range was about $38 \mathrm{~J}$ and $50 \mathrm{~J}$ for $\mathrm{M}$ and $\mathrm{P}$ specimens respectively. Nevertheless, the lower shelf energy did not seem to have been reached for the tested temperatures.

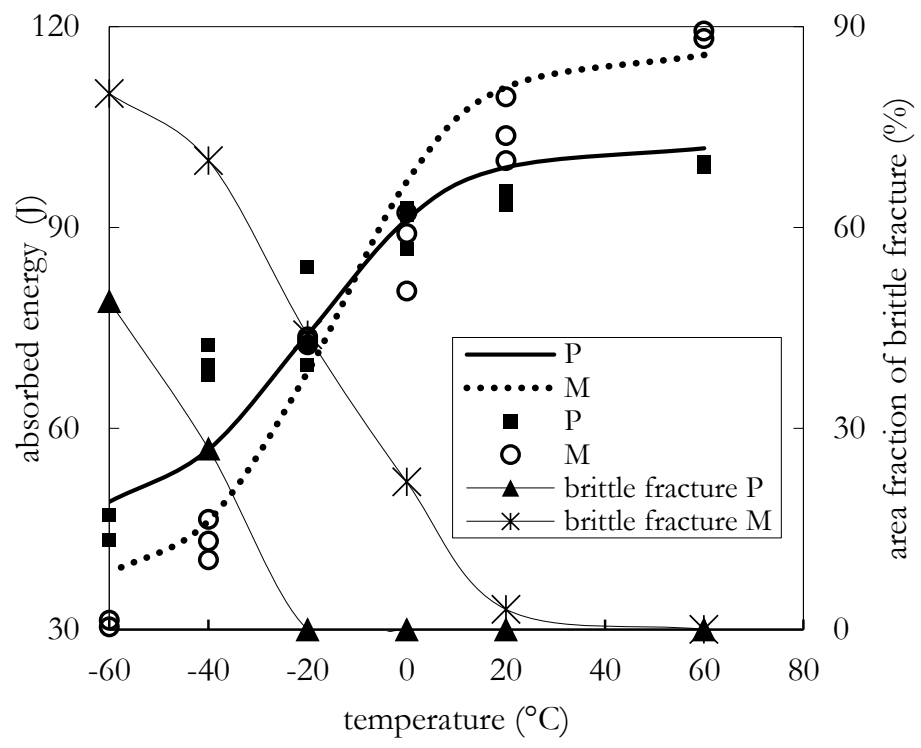

Fig. 6: Charpy impact properties of the tested steels and area fraction of brittle fracture.

Fig. 7 illustrates the corresponding fracture mechanisms at the micrometer scale. After fracture at $-60^{\circ} \mathrm{C}$ (Figs 7a, 7d), cleavage facets connected by tearing ridges were found together with many secondary cracks. Haušild et al [12] explained that secondary cracks were created after the passage of the main crack and cut the river ridges of the main crack. Increasing the test temperature up to $-20^{\circ} \mathrm{C}$ increases the fraction of ductile ligaments (Figs 7b, 7e). At room temperature (Figs 7c, 7f), ductile fracture occurred with about $90 \%$ area fraction of fine dimples $(\sim 0.3 \mu \mathrm{m})$ and of coarser dimples $(\sim 1$ $\mu \mathrm{m}$ ). Inclusions (probably sulfide or oxideparticles) were found in the coarser dimples; this was confirmed using cross-section observations. Rod-like particles were observed in the fine dimples. Their size and morphology, compared with the distributions of carbides determined from extractive replicas, suggested that fine dimples actually nucleated from $\mathrm{M}_{3} \mathrm{C}$ carbides. Due to their small size ( 200 nm), EDS analysis was not made for identification of the nature of these particles on the fracture surfaces. 

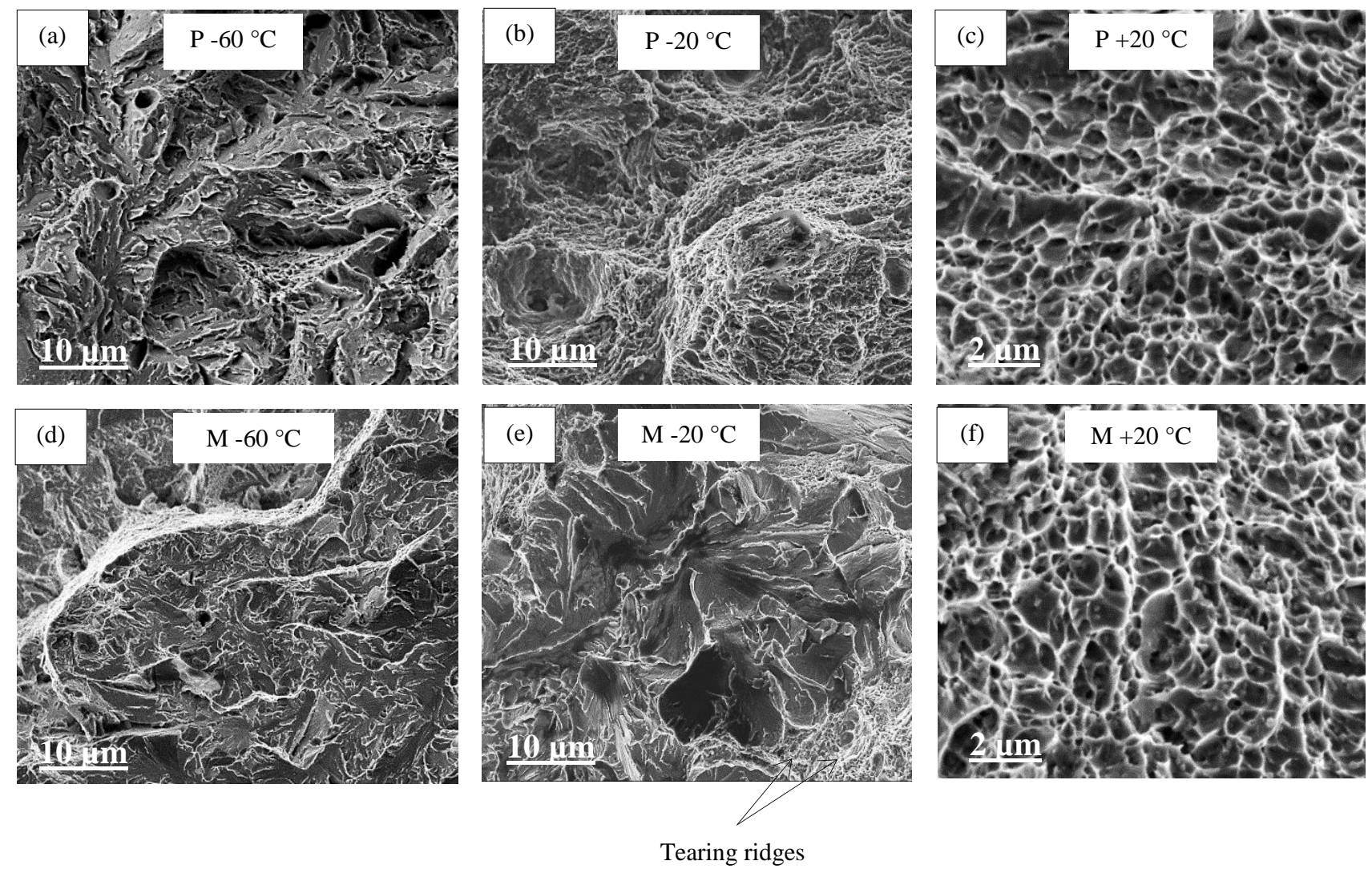

Tearing ridges

Fig. 7: Fracture surfaces of $(a, b, c) P$ and $(d, e, f) M$ Charpy specimens tested at $-60^{\circ} \mathrm{C},-20^{\circ} \mathrm{C}$ and at room temperature.

\subsubsection{Fracture initiation and fracture propagation energy}

Following the analysis of fracture energy in terms of initiation and propagation parts for martensitic steels proposed by Takebayashi et al [4], the amount of energy absorbed during initiation and propagation stages are plotted against test temperature in Figs 8a and 8b, respectively. The main tendencies were as follows: (i) there iwas no dependence of the initiation energy with temperature, even if initiation energy of $\mathrm{M}$ specimens tend to be superior to that of $\mathrm{P}$ specimens at a given test temperature ; (ii) for both microstructures, the change in fracture mechanism from brittle to ductile was correlated to a transition in propagation energy, the higher USE of M specimen being attributed to the propagation part of the ICIT curve. Fig. 9 illustrates this result with load vs. displacement curves of specimens tested at $+60^{\circ} \mathrm{C}$, i.e., in the fully ductile domain. The main difference between the two specimens was on the yielding behavior and amount of strain before crack propagation. 

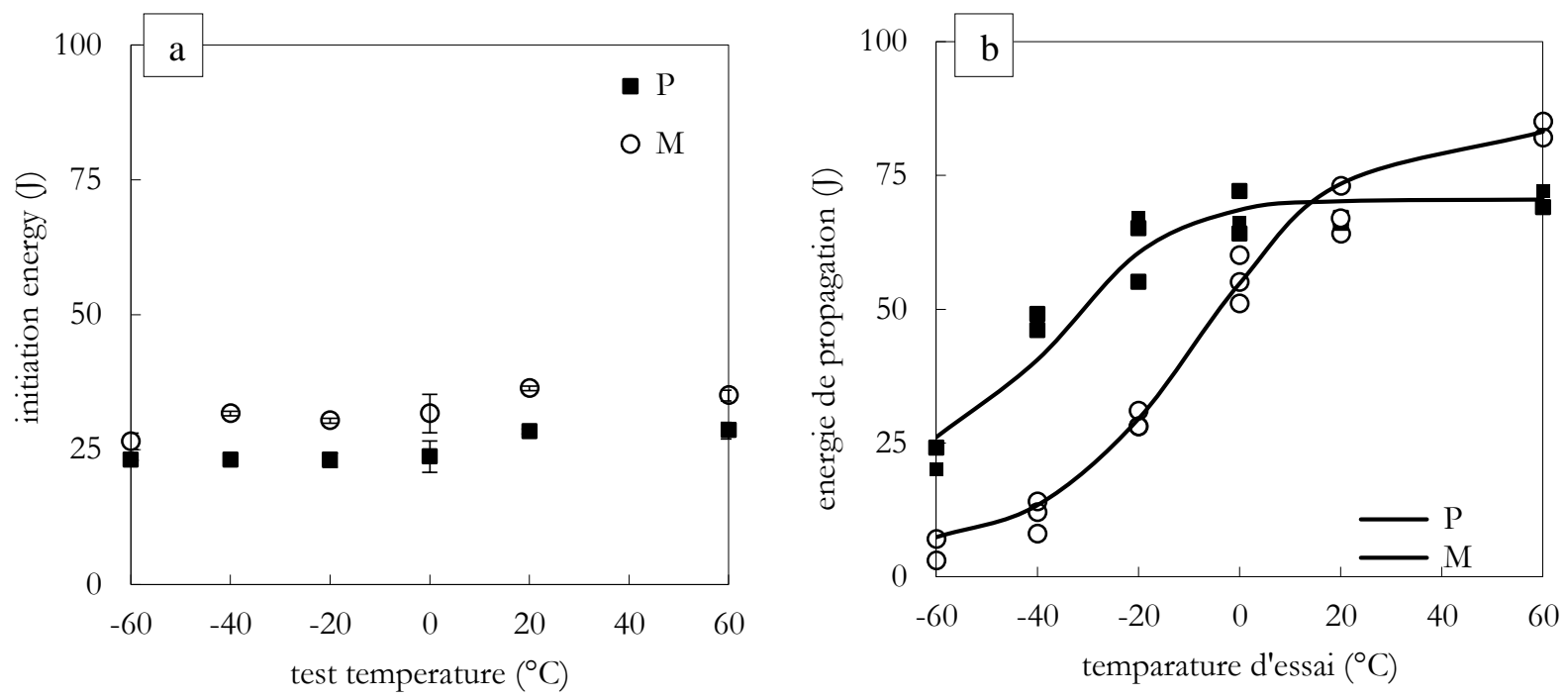

Fig. 8: Fracture initiation energy (a) and fracture propagation energy (b), plotted against test temperature.

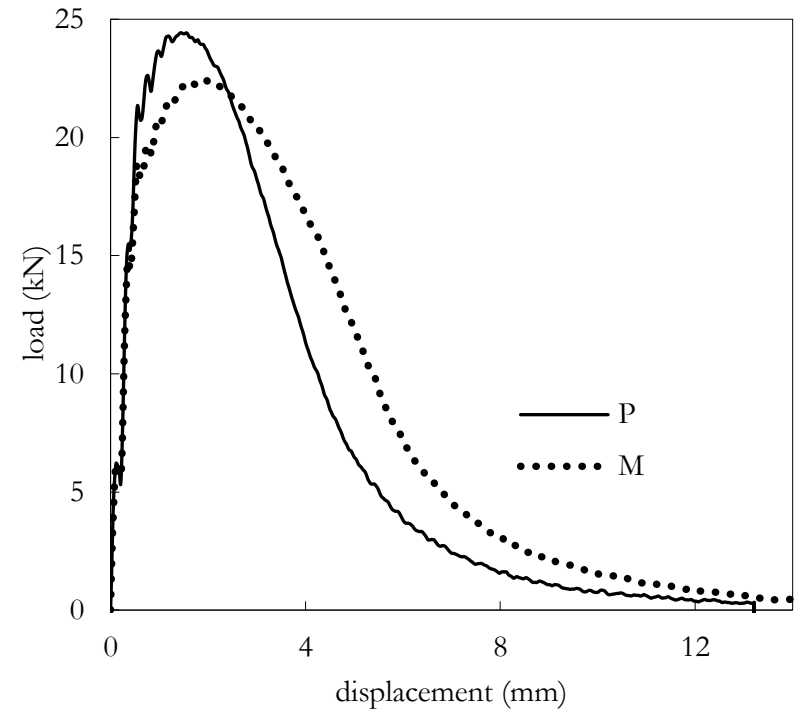

Fig. 9: ICIT waveforms of specimens tested at $+60^{\circ} \mathrm{C}$.

\subsection{Ductile-to-brittle transition behavior investigated by the local approach to fracture}

\subsubsection{Experimental results}

Load vs notch opening curves of tests on NPS specimens are plotted in Fig. 10. They confirmed that microstructure $\mathrm{P}$ was stronger than microstructure $\mathrm{M}$ at every test temperature. As already wellknown for steels having a bcc crystal structure, increasing strength and reduction of notch opening with decreasing the test temperature were noticed for the two steels, this phenomenon being clearer for microstructure P. At $-60^{\circ} \mathrm{C}$, the load drop suddenly occurred after $0.2 \mathrm{~mm}$ of notch opening for steel P. For temperatures higher than $-60^{\circ} \mathrm{C}$, fracture occurred once the maximum load had been reached. 
Fracture surfaces are illustrated in Fig. 11. At $-60^{\circ} \mathrm{C}$, fracture was globally brittle. They are identified by bright facets. Salemi et al [13] attributed bright facets on broken surfaces to the effect of inter phase boundaries on the cleavage fracture. There were also some apparently planar, but rather rough facets at lower temperature, resembling local intergranular cracking. NPS specimens tended to reveal them more frequently than Charpy specimens. One of these facets is surrounded in Fig. 11 (microstructure $\mathrm{P}$ at $-60^{\circ} \mathrm{C}$ ) by a dotted white line. It is known [2] that intergranular cracks can be sometimes attributed to reverse temper embrittlement (TE) between 450 and $600^{\circ} \mathrm{C}$ and linked to segregation of impurities during tempering $(\mathrm{P}, \mathrm{Sn}, \mathrm{As}, \mathrm{Sb})$ at grain boundaries during tempering. Nevertheless, the tempering temperatures used in the present study were higher. In the ductile regions, large and fine dimples were initiated respectively from $\mathrm{MnS}$ particles and $\mathrm{M}_{3} \mathrm{C}$ carbides, as in Charpy specimens. Up to rather high temperatures (about $+40^{\circ} \mathrm{C}$ ), fracture surfaces of microstructure $\mathrm{M}$ showed many coarse cleavage facets corresponding to upper bainite; in fact, cleavage facets of martensite, which dominated the lower temperature fracture surfaces (see fractographs at $-60^{\circ} \mathrm{C}$ ) appeared much finer due to the intricate microtexture of martensite variants.
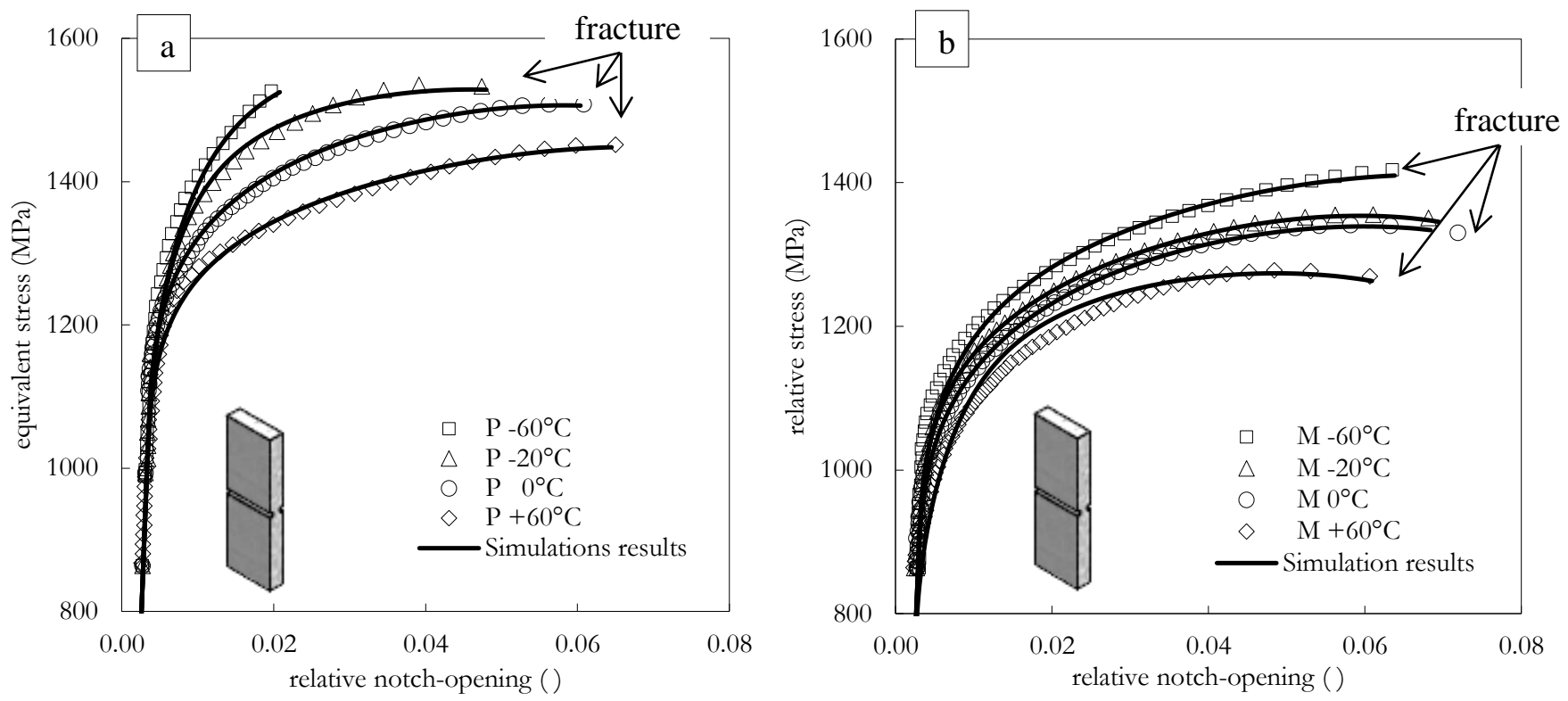

Fig. 10: Results of tensile tests at different temperatures on NPS specimens of (a) microstructure P (b) microstructure M. 


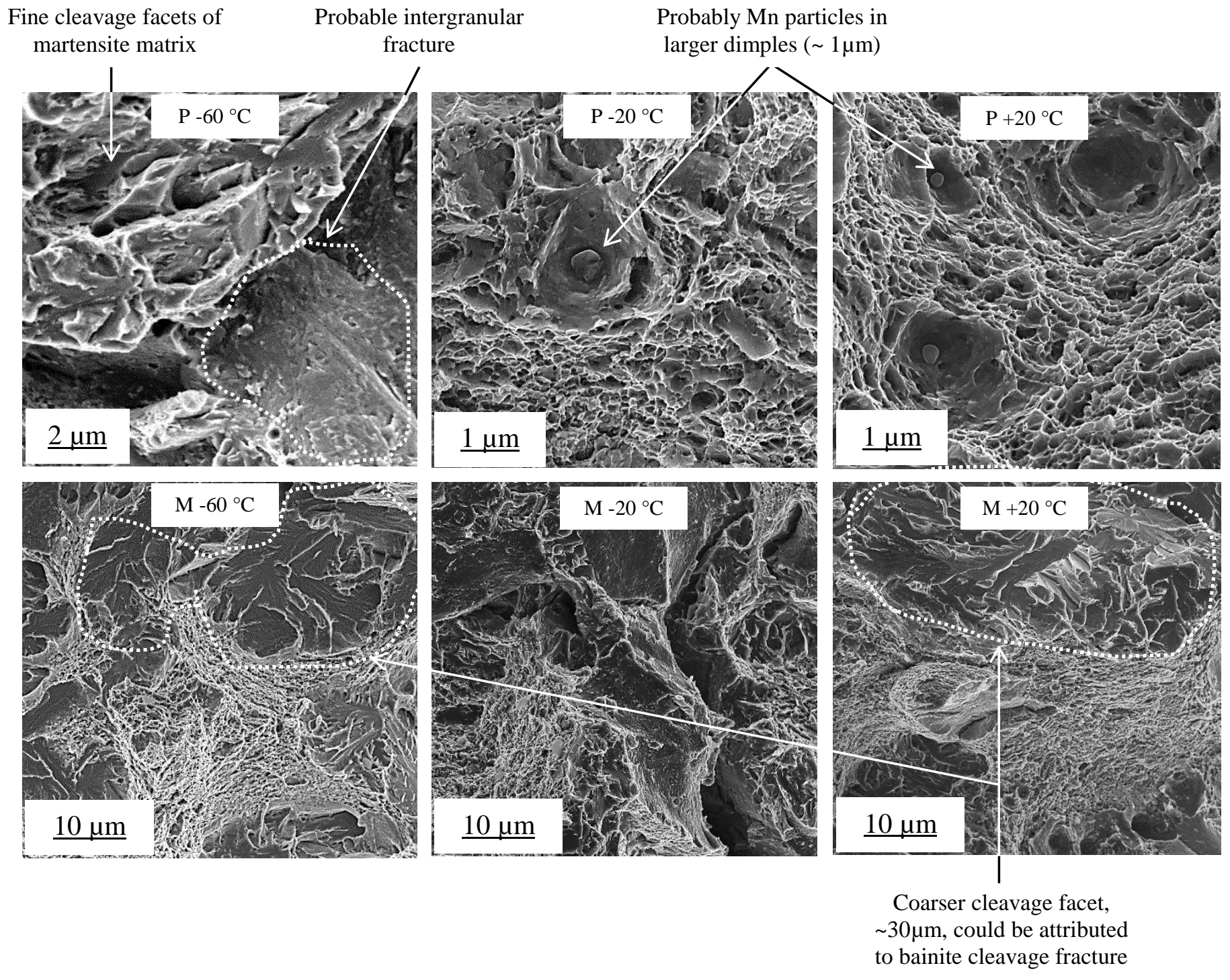

Fig. 11: Fracture surfaces of the double-side notched plane strain specimens tested in tensile at $-60^{\circ} \mathrm{C},-20^{\circ} \mathrm{C}$ and at room temperature.

\subsubsection{Mechanical analysis}

Identification and optimization of constitutive equations of the two steels were performed on Zset ${ }^{\circledR}$ in-house finite element software. The numerical procedures are identical to that reported in [13]. First, a coupled-optimization was made based on the experimental results obtained on SC and SPS specimens at room temperature. For uniaxial tension of SC specimens, only the part of the curve before necking was considered. The entire load-displacement curve for SPS specimens was simulated. Subsequently, optimized parameters were used for the numerical calculation of tests on SPS specimens.

The plastic flow behavior of the two microstructures could be well described by a Hosford yield locus, $f$ (Eq. 1), the usual normality rule for plastic strain together with nonlinear isotropic hardening (Eq. 2, p being the cumulative plastic strain), the loading path being approximately radial in the stress space: 


$$
\begin{aligned}
& f(\sigma, p)=\sigma_{H}-R(p) \text { with } \sigma_{H}=\sqrt[n]{\frac{\left(\sigma_{1}-\sigma_{2}\right)^{n}+\left(\sigma_{2}-\sigma_{3}\right)^{n}+\left(\sigma_{1}-\sigma_{3}\right)^{n}}{2}} \\
& R(p)=R_{o}+\sum_{i} Q_{i}\left(1-e^{-b_{i} p}\right), i=1,2,3
\end{aligned}
$$

In Eq. (1), $\sigma_{1}>\sigma_{2}>\sigma_{3}$ are the eigenvalues of the usual deviator part of the stress tensor, $\sigma$. In Eqs (12), $Q_{i}, n$ and $b_{i}$ are material parameters. $R_{o}$ is the initial yield strength. In the optimization procedure, the Young modulus and Poisson's ratio were set to $200 \mathrm{GPa}$ and 0.3 , respectively, for both microstructures. To guide the optimization of material parameters, the maximum uniform elongation for SC tests was forced to fit with experimental data through an additional relationship between material parameters. To this aim, the Considère criterion (Eq. 3) was applied as follows:

$$
\frac{d R}{d p}=R \text { at the onset of load decrease, }
$$

from which one obtains $R_{o}-\sum_{i} Q_{i}\left[\left(1+b_{i}\right) e^{-b_{i} p_{\text {crit }}}-1\right]=0, i=1,2,3$

where $p_{\text {crit }} \sim 0.058$

Optimized parameters for the behavior of tensile test on PS specimens at room temperature are presented in Table 2. From Fig. 4, good agreement with experimental results was obtained. This allowed the stress state in the various specimens to be estimated at the onset of fracture (see section

\begin{tabular}{|c|c|c|c|c|c|c|c|c|c|}
\hline \multirow{4}{*}{$\begin{array}{l}\text { Hardening } \\
\text { rule }\end{array}$} & \multicolumn{9}{|c|}{ parameters } \\
\hline & specimens & $n$ & $\mathrm{Ro}(\mathrm{MPa})$ & $\mathrm{Q}_{1}(\mathrm{MPa})$ & $b_{1}$ & $\mathrm{Q}_{2}(\mathrm{MPa})$ & $b_{2}$ & $\mathrm{Q}_{3}(\mathrm{MPa})$ & $b_{3}$ \\
\hline & $\mathrm{P}$ & 7 & 874 & 241 & 81 & 312 & 4 & 106 & 0.1 \\
\hline & M & 7 & 800 & 216 & 62 & 214 & 4 & 102 & 0.1 \\
\hline
\end{tabular}
4.2).

Table 2: Optimized parameters of the constitutive equations at room temperature

\section{Discussion: comparison between fracture behavior in Charpy tests and in quasistatic tests on notched plane strain specimens}

\subsection{Fracture mechanisms}

Impact toughness results showed that in the USE range, microstructure $M$ was tougher than microstructure $\mathrm{P}$. On the one hand, only $\mathrm{M}_{3} \mathrm{C}$ carbides were observed in the fine dimples. On the other hand, the nearest-neighbor distance between $\mathrm{M}_{3} \mathrm{C}$ carbides is nearly the same for microstructures $\mathrm{P}$ and M. So the only difference was on the average size of these carbides. The lower USE of microstructure $\mathrm{P}$ could be due to the fact that carbides were by $0.03 \mu \mathrm{m}$ larger than those of microstructure $\mathrm{M}$, ductile crack initiation being possibly easier than on microstructure M. Nevertheless, the only effect of carbides could probably not explain the difference in USE. The higher impact toughness of microstructure $\mathrm{M}$ in the USE range could also be attributed to bainite. The lower strength of bainite- 
containing microstructure $\mathrm{M}$ was probably overwhelmed by its higher resistance to ductile crack initiation, leading to higher fracture initiation energy.

As soon as brittle fracture appeared, the detrimental effect of bainite drastically reduced the fracture energy of microstructure M. Fig. 12 shows that in contrast with the fracture mechanisms of Charpy impact specimens, NPS specimens tended to enhance differences between transition regions of the two microstructures. From the coarse size $(20 \mu \mathrm{m})$ of cleavage facets observed on NPS specimens of microstructure $\mathrm{M}$ up to warm temperatures, this brittle behavior could be attributed to a higher cleavage-to-ductile transition temperature of bainite in NPS specimens than in Charpy specimens. On the contrary, microstructure $\mathrm{P}$ showed good agreement between fracture mechanism transition temperatures obtained with NPS specimens and with Charpy specimens, respectively. This could indicate that quasistatic tests on NPS specimens could be more sensitive than conventional Charpy impact tests to microstructural features that exhibit a lower resistance to brittle cleavage (micro) cracking.

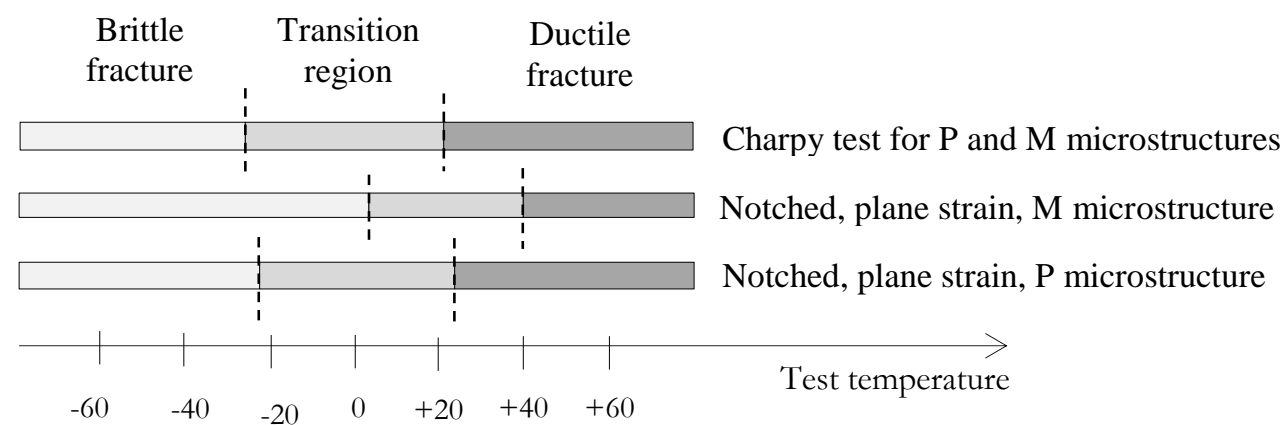

Fig. 12: Comparison of fracture appearance transition behaviors between Charpy impact tests specimens and quasi-static tensile tests on NPS specimens.

\subsection{Comparison of Stress states between Charpy and NPS specimens}

Stress states between Charpy quasi-static and NPS specimens were compared by considering the evolution of the three principal stresses, stress triaxiality $\eta$ and Lode parameter $L$ ahead of the notch tip. All the distributions were calculated along the ligament at the center of Charpy V-notch and NPS specimens. The position $x$ along the ligament was normalized by $\omega$, the distance from the tip of the notch to the center of the NPS geometry, and the initial length of the ligament for Charpy specimens. This normalizing distance is respectively $\omega=1.5 \mathrm{~mm}$ and $\omega=8 \mathrm{~mm}$ for NPS and Charpy geometry. As presented in Fig. 13 (a), the principal stresses (S1, S2 and S3) for the two geometries increase, then decrease steadily with increasing the distance to notch tip. For the two geometries, S1 keeps significantly higher values while S2 and S3 tend to keep similar values farther from the notch tip. Fig. 13 (b) plots evolution of $\eta$ and $L$ close to the tip of the notch. They have same tendency for the two geometries, at least close to the crack initiation locus (i.e. close to the mid-thickness of the NPS specimens and about $0.25 \mathrm{~mm}$ from the nocth tip of the Charpy specimen). 

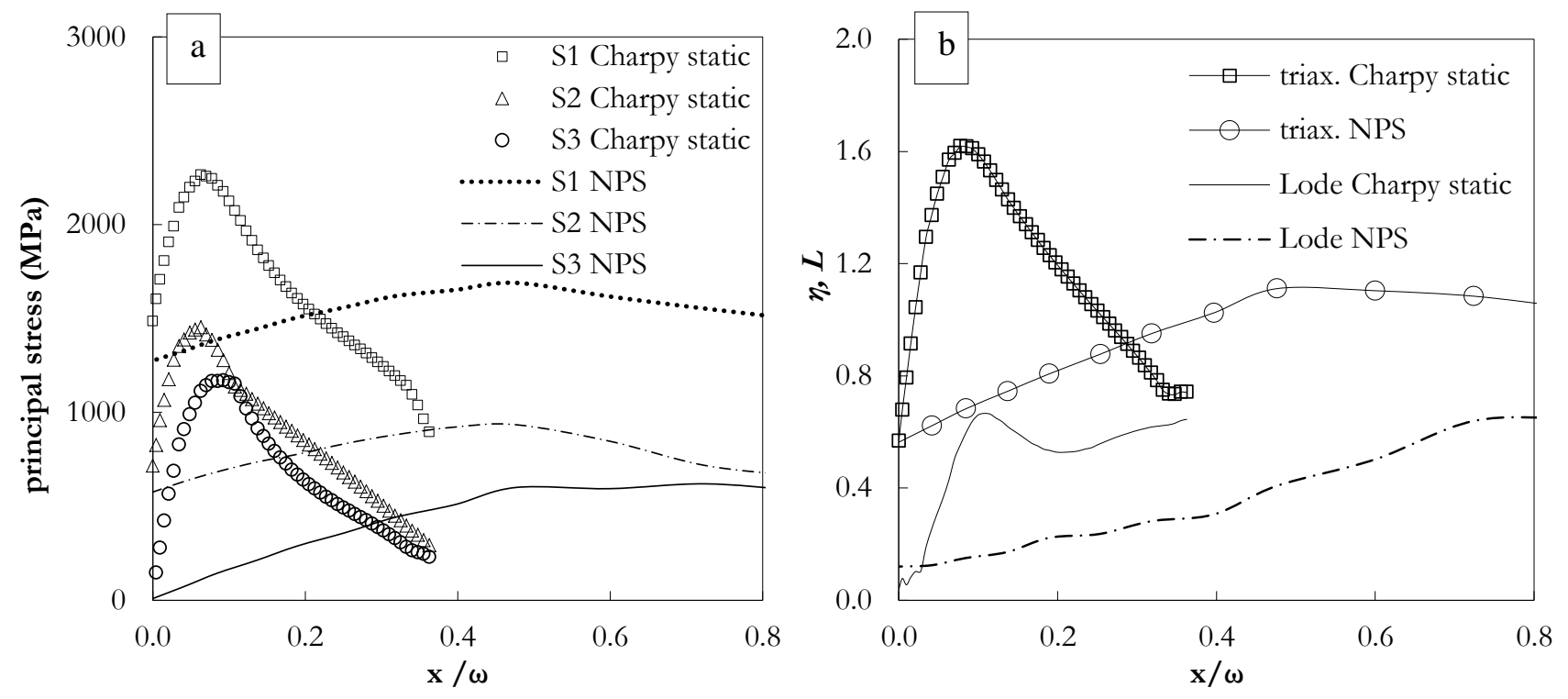

Fig. 13: Comparison of estimated evolutions of (a) principal stresses ahead of the notch tip and (b) estimated stress triaxiality and Lode parameter along the ligament between (static) Char^py and NPS specimens.

\section{Conclusion}

In the present work, two microstructures $\mathrm{P}$ and $\mathrm{M}$ taken from the same bar of a high strength quenched + tempered martensitic steel were study by instrumented Charpy tests and tensile tests on double-side notched plane strain specimens. The main conclusions are as follows:

1. In both tests, ductile fracture initiated from coarser voids nucleated from inclusions, then from finer voids nucleated from coarse cementite particles; finer carbides seem to be too small to initiate fracture during plastic deformation.

2. From Charpy tests, the ductile-to-brittle transition in impact energy was mainly attributed to a transition in propagation energy; nevertheless, the initiation energy steadily increased with temperature, being higher for microstructure $\mathrm{M}$ at higher temperatures, and lower at lower temperatures. This difference dominated the difference in USE between the two microstructures.

3. In addition to the slight effect of the $\mathrm{M}_{3} \mathrm{C}$ carbides, the presence of bainite within the microstructure of steel $\mathrm{M}$ tends to contribute significantly to the USE. On the other hand, upper bainite was responsible for the lower resistance of microstructure $M$ to brittle fracture, leading to lower fracture energy in the low-temperature range.

4. Tensile tests on notched plane strain specimens were in qualitative agreement with Charpy results, yet being more sensitive to the cleavage fracture of bainite.

5. Analysis of stress state show qualitatively similar loading conditions, in particular concerning the Lode parameter, between NPS and Charpy geometriez analyzed in quasi-static conditions. 
The development of a ductile fracture criterion for $\mathrm{P}$ and $\mathrm{M}$ specimen is in progress, were are also developing a predictive fracture energy tools by using test in quasi-static conditions.

\section{Acknowledgments}

The authors would like to express their gratitude to Franck N'GUYEN for the development of the numerical SKIZ analysis tool, to Gerard BRABANT, Antoine DEBRAY and Kevin BARRIERE for having performed some of the scanning electron microscopy analysis. This work is supported by ANRT (French innovation supporting agency) under Grant CIFRE 2016/0670.

\section{References}

[1] G. Béranger, G. Henry, G. Labbe, and P Soulignac, Les aciers spéciaux, Lavoisier. Paris, 1997.

[2] M. Saby and T. Sourmail, 'Rapport d'avancement sur la connaissance de la trempe-revenu des nuances Oil\&Gas', Ascometal CREAS, CREAS R 2014-15, September. 2014.

[3] Y. Tomita, 'Low- Temperature improvement of mechanical properties of aisi 4340 steel through hightemperature thermomechanical treatment', Metall. Trans. A, vol. 22, no. 5, pp. 1093-1102, May 1991.

[4] S. Takebayashi, K. Ushioda, N. Yoshinaga, and S. Ogata, 'Effect of Carbide Size Distribution on the Impact Toughness of Tempered Martensitic Steels with Two Different Prior Austenite Grain Sizes Evaluated by Instrumented Charpy Test', Mater. Trans., vol. 54, no. 7, pp. 1110-1119, 2013.

[5] Y.-R. Im, Y. Jun Oh, B.-J. Lee, J. Hwa Hong, and H.-C. Lee, 'Effects of carbide precipitation on the strength and Charpy impact properties of low carbon Mn-Ni-Mo bainitic steels', J. Nucl. Mater., vol. 297, no. 2, pp. 138-148, August 2001.

[6] A. Pineau, 'Development of the Local Approach to Fracture over the Past 25 years: Theory and Applications', Int. J. Fract., vol. 138, no. 1-4, pp. 139-166, 2006.

[7] L. Xue and T. Wierzbicki, 'Ductile fracture initiation and propagation modeling using damage plasticity theory', Eng. Fract. Mech., vol. 75, no. 11, pp. 3276-3293, July 2008.

[8] T. Wierzbicki, Y. Bao, Y.-W. Lee, and Y. Bai, 'Calibration and evaluation of seven fracture models', Int. J. Mech. Sci., vol. 47, no. 4-5, pp. 719-743, April 2005.

[9] H. Kim, J. Park, M. Kang, and S. Lee, 'Interpretation of Charpy impact energy characteristics by microstructural evolution of dynamically compressed specimens in three tempered martensitic steels', Mater. Sci. Eng. A, vol. 649, pp. 57-67, Jan. 2016.

[10]P. R. Sreenivasan, S. K. Ray, S. L. Mannan, and P. Rodriguez, 'Dynamic fracture toughness and Charpy impact properties of an AISI 403 martensitic stainless steel', J. Nucl. Mater., vol. 228, no. 3, pp. 338-345, April 1996.

[11]P. Haušild, I. Nedbal, C. Berdin, and C. Prioul, 'The influence of ductile tearing on fracture energy in the ductile-to-brittle transition temperature range', Mater. Sci. Eng. A, vol. 335, no. 1-2, pp. 164-174, September 2002.

[12]A. Salemi, A. Abdollah-Zadeh, M. Mirzaei, and H. Assadi, 'A study on fracture properties of multiphase microstructures of a CrMo steel', Mater. Sci. Eng. A, vol. 492, no. 1-2, pp. 45-48, September 2008.

[13]J. Lorthios, M. Mazière, X. Lemoine, P. Cugy, J. Besson, and A.-F. Gourgues-Lorenzon, 'Fracture behaviour of a Fe-22Mn-0.6C-0.2V austenitic TWIP steel', Int. J. Mech. Sci., vol. 101, pp. 99-113, October 2015. 